Belowground fungal communities in pioneer Scots pine stands growing on heavy metal polluted and non-polluted soils

Peer-reviewed author version

OP DE BEECK, Michiel; RUYTINX, Joske; SMITS, Mark; VANGRONSVELD, Jaco; COLPAERT, Jan \& RINEAU, Francois (2015) Belowground fungal communities in pioneer Scots pine stands growing on heavy metal polluted and non-polluted soils. In: SOIL BIOLOGY \& BIOCHEMISTRY, 86, p. 58-66.

DOI: 10.1016/j.soilbio.2015.03.007

Handle: http://hdl.handle.net/1942/19004 


\title{
Belowground fungal communities in pioneer Scots pine stands growing on heavy metal polluted and non-polluted soils
}

\author{
Michiel Op De Beeck, Joske Ruytinx, Mark M. Smits, Jaco Vangronsveld, Jan V. Colpaert, François \\ Rineau \\ Hasselt University, Centre for Environmental Sciences, Environmental Biology Group, Hasselt, \\ Belgium
}

\begin{abstract}
The impact of soil metal pollution on plant communities has been studied extensively in the past. However, very little is known about the fungal species that co-occur with these plant communities on metal polluted soils. We characterized the belowground fungal community in a heavy metal polluted and a non-polluted soil using 454 pyrosequencing. The fungal communities at both study sites were shown to consist mainly of the same ectomycorrhizal species, but a consistent shift in the relative abundances of these species was observed, whereas no differences in fungal diversity were found. In metal polluted soil, root tips of young pines were initially largely colonized by stress-tolerant dark Ascomycota that were mostly replaced by metal-tolerant Basidiomycota within 2 years. Compared to older forests a low belowground fungal diversity was observed in the two pioneer stands.
\end{abstract}

Keywords: metal pollution, fungal community, succession, metabarcoding, 454 pyrosequencing

\section{INTRODUCTION}

Worldwide, vast areas have become contaminated with high concentrations of heavy metals due to pyrometallurgical industry and mining activities. High concentrations of metal ions in soils have been found to have detrimental effects on fungal, plant and bacterial communities. Ernst (1990) for example, observed a decrease in floristic diversity along a metal pollution gradient towards metal smelters. Hence, plant communities thriving on metalliferous soils often consist of well-adapted plant species, some of which may even be endemic to a restricted number of metalliferous sites. For example, the Violetum calaminariae association is a plant community occurring exclusively in small areas in Belgium and Germany where metal-rich ores surface (Schwickerath, 1944). In contrast to our vast and long-standing knowledge on plant communities that thrive on metal polluted soils, far less is known about the effects of heavy metal pollution on the diversity and community composition of fungal species that occur in heavy metal polluted soils.

Few authors found evidence that fungal species diversity might be lower in highly polluted soils compared to non-polluted ones (Staudenrausch et al., 2005). Hui et al. (2011), studying ectomycorrhizal (ECM) fungal communities in lead contaminated soils, observed shifts in the composition of the communities, but the heavy metal pollution did not strongly affect fungal diversity. Up to now, most researchers used biomarkers (e.g. phospholipid fatty acids) to investigate differences in fungal community composition amongst polluted and non-polluted soils (e.g. Chodak et al., 2013; Corneo et al., 2013). Although such studies can reveal shifts in fungal community composition, they generally cannot pinpoint the identity of those fungi that are affected by the metal stress. It is expected that fungal species that exhibit heavy metal tolerance and/or resistance mechanisms would have a selective advantage under toxic conditions over more sensitive species. 
So far, no fungal species have been described to have a distribution restricted to heavy metal polluted soils. However, a few species have been identified repeatedly from roots of plants growing on severely heavy metal polluted soils. For example, dark pigmented ectomycorrhizal Ascomycota (e.g. Helotiales) are remarkably frequent on roots from woody plants growing on copper polluted sites in Norway (Vrålstad et al., 2000, 2002). Dark septate root endophytes (DSE) belonging to the Phialophora/Cadophora complex were identified from Salix caprea L. roots growing in very toxic soil close to a lead smelter in Slovenia (Likar and Regvar, 2009, 2013). The latter authors observed a dominance of root associated Ascomycota in the most polluted plots, whereas there was a greater diversity of Basidiomycota in the less polluted and control plots, suggesting greater stress tolerance of these Ascomyceta in comparison to Basidiomycota. Several DSE fungi were also identified in an ancient $\mathrm{Pb}-\mathrm{Zn}$ slag heap in Southwest China (Zhang et al., 2013) and Bradley et al. (1981) demonstrated that the ericoid mycorrhizal ascomycete Rhizoscyphus (=Hymenoscyphus) ericae (D.J. Read) W.Y. Zhuang \& Korf supported the survival of Calluna vulgaris (L.) Hull on acidic copper, zinc and lead polluted soils in the UK. Relatively few basidiomycetes have been reported repeatedly from heavy metal polluted sites, except for Suillus and Pisolithus species (Colpaert et al., 2004; Adriaensen et al., 2005; Jourand et al., 2010).

Recent developments in molecular biology, such as 454 pyrosequencing (Margulies et al., 2005), now enable us to study which fungal species are able to colonize heavy metal polluted soils in unprecedented detail. Knowledge on the fungal communities from these metal polluted soils is not only important for our general understanding of the functioning of natural ecosystems in stressful environments, this knowledge may also help us in developing strategies to remediate polluted areas (Turnau et al., 2008; Solíz-Domínguez et al., 2011). Furthermore, a thorough understanding of the impact of metal pollution on fungal diversity and fungal community dynamics is necessary to understand the faith of fungi and plants after their introduction to metal polluted environments.

Therefore, the aims of the current study were to investigate the effects of heavy metal pollution on fungal community composition and diversity during early colonization of heavy metal polluted soils using a metabarcoding approach.

\section{MATERials AND Methods}

\section{1. Study sites and sampling}

Fungal communities were sampled in two pioneer Scots pine forests (Pinus sylvestris L.) growing on sandy soils in the Campine region in Belgium. The first fungal community was sampled in a metal polluted site in Lommel-Maatheide (LM: $\left.51^{\circ} 14^{\prime} 10^{\prime \prime} \mathrm{N} ; 5^{\circ} 15^{\prime} 50^{\prime \prime} \mathrm{E}\right) . \mathrm{Ca}\left(\mathrm{NO}_{3}\right)_{2}$ extractable soil $\mathrm{Zn}$ and $\mathrm{Cd}$ concentrations in this site range from 1 to $197 \mu \mathrm{g} \mathrm{g}^{-1}$ dry weight (d. wt) $\mathrm{Zn}$ and $<0.1$ to 1.56 $\mu \mathrm{g} \mathrm{g}^{-1} \mathrm{~d}$. wt Cd. The second site is situated in Hechtel-Eksel (HE: $51^{\circ} 7{ }^{\prime} 33^{\prime \prime} \mathrm{N}, 5^{\circ} 22^{\prime} 22^{\prime \prime}$ E). This site is hardly polluted by pyrometallurgical activities and is used as a reference site in this study. $\mathrm{Ca}\left(\mathrm{NO}_{3}\right)_{2}$ extractable soil $\mathrm{Zn}$ concentrations in this site range from 3 to $13 \mu \mathrm{g} \mathrm{g} \mathrm{g}^{-1} \mathrm{~d}$. wt and $\mathrm{Cd}$ concentrations were below the detection limit of $0.1 \mu \mathrm{g} \mathrm{g}^{-1} \mathrm{~d}$. wt. Mosses and lichens form the main accompanying primary pioneer vegetation at both sites. The pioneer grass species Corynephorus canescens Horst occurs sparsely throughout both study sites and in HE, a few Calluna vulgaris shrubs are present as well. The soil at both study sites is a dry sandy soil without a litter layer, poor in organic matter and slightly acidic. The average soil organic matter $(\mathrm{OM})$ content in HE was $0.7 \% \pm$ $0.1 \%$ (standard error) and the average $\mathrm{pH}$ (measured in $\mathrm{KCl}$-extracts) was $4.5 \pm 0.02$. In $\mathrm{LM}$, the average $\mathrm{OM}$ content was $0.8 \% \pm 0.1$ and the average $\mathrm{pH}$ was $4.6 \pm 0.07$. More detailed information on measured environmental variables in LM and HE can be found in Fig. S1. The region has an average annual rainfall of $800 \mathrm{~mm}$ and the average annual temperature is $10^{\circ} \mathrm{C}$ (Royal Meteorological Institute, Ukkel, Belgium). 
The pioneer forest in LM is growing on a site where polluted topsoil was removed in 2004. This disturbance introduced heterogeneity in the newly exposed soil and resulted in large differences in metal concentrations over short distances. To estimate the overall metal exposure of individual pine trees in LM, soil samples and last-year pine needles from 22 one-year old (in 2009) trees were collected for $\mathrm{Zn}$ and $\mathrm{Cd}$ analysis. Finally, a subset of 10 trees from LM containing between 200 and $400 \mu \mathrm{g} \mathrm{Zn} \mathrm{g}{ }^{-1} \mathrm{~d}$. wt in needles were selected for the fungal community analysis. Needles of these trees were not chlorotic, though the critical leaf tissue concentrations affecting growth in most plants ranges from 200 to $300 \mu \mathrm{g} \mathrm{Zn} \mathrm{g}^{-1} \mathrm{~d}$. wt (Påhlsson, 1989). Needle $\mathrm{Zn}$ concentrations are a good measure for the actual $\mathrm{Zn}$ exposure of individual trees (Colpaert et al., 2004).

The $10 \mathrm{LM}$ trees were compared to 10 one-year old trees from HE, containing 20 to $90 \mu \mathrm{g} \mathrm{Zn} \mathrm{g}{ }^{-1} \mathrm{~d}$. wt in needles (Fig. S1). Selected pine trees were at least $20 \mathrm{~m}$ apart from each other. The pioneer forest in HE is growing on a stabilized sand dune.

For the characterization of fungal communities, soil and root tip samples were collected at both sites in November 2009 and in November 2011. Soil samples were collected with a soil corer with a diameter of $1 \mathrm{~cm}$ at a depth of $0 \mathrm{~cm}$ to $20 \mathrm{~cm}$. For each tree, five samples were collected according to the cardinal directions at different distances from the stem. These included samples collected immediately next to stems and at a distance of $25 \mathrm{~cm}, 50 \mathrm{~cm}, 75 \mathrm{~cm}$ and $100 \mathrm{~cm}$ from stems (Fig. S2). Samples were pooled for each of these distances and mixed, resulting in a total of five pooled samples for each tree with each sample representing a certain distance from the stem. Additionally, roots from selected pine trees were collected in both sampling years. Two long roots were unearthed per tree from the stem base up to the growth tip of the roots. In the lab, roots were washed with tap water to remove most adhering soil. For each tree, all visible short root tips were collected from the entire length of the long roots, pooled and homogenized. Root tip samples were stored at $-80^{\circ} \mathrm{C}$ until DNA extraction. Soil samples for fungal community analysis were homogenized, sieved with a $2 \mathrm{~mm}$ sieve to remove small stones, roots, and other debris, and stored at $-80^{\circ} \mathrm{C}$ until DNA extraction. Samples for physical and chemical soil characterization were collected next to each tree with a soil corer with a diameter of $10 \mathrm{~cm}$ at a depth of 0 to $20 \mathrm{~cm}$. These samples were dried at ambient temperature for two weeks before physical and chemical analyses were conducted. Collected pine needles were dried for two weeks at $60{ }^{\circ} \mathrm{C}$ before being analysed for their metal content.

\section{2. Soil physical and chemical characterization}

$\mathrm{pH}$ was measured in both a water extract (10 g soil extracted with $25 \mathrm{ml}$ distilled water) and a $\mathrm{KCl}$ extract $(10 \mathrm{~g}$ soil extracted with $25 \mathrm{ml} 1 \mathrm{M} \mathrm{KCl})$ of soil samples. Conductivity was measured on the water extracts. Soil organic matter content (OM) was analysed with the Walkley and Black method (Walkley and Black, 1934). Cation exchange capacity (CEC) was measured according to Rhoades' method (Rhoades, 1982). Exchangeable cations were extracted using $0.1 \mathrm{M} \mathrm{Ca}\left(\mathrm{NO}_{3}\right)_{2}(25 \mathrm{ml}$ for $5 \mathrm{~g}$ soil). Dried pine needles were digested with nitric acid (65\%) and hydrochloric acid $(37 \%)$ at $120^{\circ} \mathrm{C}$. Concentrations of zinc $(\mathrm{Zn})$, cadmium $(\mathrm{Cd})$, iron $(\mathrm{Fe})$, magnesium $(\mathrm{Mg})$, potassium $(\mathrm{K})$, copper $(\mathrm{Cu})$ and manganese $(\mathrm{Mn})$ were measured with inductively-coupled plasma - optical emission spectroscopy (ICP-OES) in samples obtained from calcium nitrate soil extracts and in pine needle digests. Calcium (Ca) was only measured in pine needle digests.

\section{3. Characterization of the fungal communities}

To characterize the fungal communities in soil and root tip samples, DNA was extracted using the UltraClean soil DNA isolation kit (MoBio, Carlsbad, CA, USA) from approximately $250 \mathrm{mg}$ of soil or root tips according to the manufacturer's instructions. DNA was extracted in quadruplicate from each sample and replicated extracts were pooled per sample prior to PCR amplification using the 
ITS86F forward primer (Vancov and Keen, 2009) and ITS4 reverse primer (Gardes and Bruns, 1993). This primer pair was shown to efficiently amplify the fungal internal transcribed spacer 2 (ITS2) region and characterize fungal communities using 454 pyrosequencing (Op De Beeck et al., 2014). "Fusion" primers, required for the 454 process, were designed according to the guidelines for $454 \mathrm{GS}-$ FLX Titanium Lib-A sequencing containing the Roche 454 pyrosequencing adapters and a 10-bp multiplex identifier (MID) barcode in between each adapter and primer sequence (Table S1). DNA was amplified using a Techne TC-5000 thermocycler (Bibby Scientific Limited, Staffordshire, UK) under the following conditions: initial denaturation at $95^{\circ} \mathrm{C}$ for 2 minutes, followed by 40 cycles of denaturation at $95^{\circ} \mathrm{C}$ for 30 seconds, annealing at $55^{\circ} \mathrm{C}$ for 30 seconds and extension at $72^{\circ} \mathrm{C}$ during 1 minute. A final extension phase was performed at $72^{\circ} \mathrm{C}$ during 10 minutes. Reactions were carried out in $25 \mu \mathrm{l}$ reaction volumes using the FastStart High Fidelity PCR System (Roche Applied Science, Mannheim, Germany). Each reaction contained $2.75 \mu 1$ FastStart 10x reaction buffer, $1.8 \mathrm{mM} \mathrm{MgCl}$, $0.2 \mathrm{mM}$ dNTP mix, $0.4 \mu \mathrm{M}$ of each primer, $1.25 \mathrm{U}$ FastStart HiFi polymerase and $5 \mathrm{ng}$ template DNA (as measured by a Nanodrop spectrophotometer). Amplified DNA was cleared from PCR primers and primer dimers using the Agencourt AMPure XP system according to the manufacturer's protocol (Beckman Coulter, Brea, CA, USA). Next, purified DNA was quantified with the Quant-iT PicoGreen dsDNA Assay Kit (Invitrogen, Carlsbad, CA, USA) and a Fluostar Omega plate reader (BMG Labtech, Ortenberg, Germany) and pooled into five equimolar amplicon libraries $\left(10^{7}\right.$ molecules per $\mu 1)$ of 40 to 50 samples. Each of the five resulting amplicon pools were sequenced on one fourth of a Pico Titerplate on a Roche Genome Sequencer FLX system using Titanium chemistry (Roche Applied Science, Mannheim, Germany) according to the manufacturer's instructions.

The information in the five Standard Flowgram Format (SFF) files that resulted from the interpreted flowgrams was combined in a single quality and a fasta file using a custom Python script. Further analyses were performed in Mothur 1.31.2 (Schloss et al., 2009). Quality trimming in Mothur was used to remove reads shorter than 200 bases, reads longer than 600 bases, reads containing homopolymers longer than 8 bases and reads containing ambiguous bases. Reads were trimmed when the average Phred quality score dropped below 35 over a window of 50 bases (Schloss et al., 2009). Next, sequences were compared to each other and duplicate sequences were replaced by a single sequence, while archiving the abundance data of the unique sequences. Unique reads were checked for chimeric sequences with the Uchime software implemented in Mothur and chimeric sequences were removed from the dataset. Unique reads were subsequently aligned with the pairwise alignment tool in Mothur, using default settings. Finally, species-level operational taxonomic units (OTUs) were defined based on a $97 \%$ sequence similarity cut-off, which is generally within the range of intraspecific ITS sequence similarity (Blaalid et al., 2013). In order to further remove potential sequencing errors from the dataset, singletons were removed (Tedersoo et al., 2010). Subsequently, rarefaction curves at the level of individual trees were constructed and Good's coverage was calculated with Mothur for each tree. OTU richness, Pielou evenness scores and inverse Simpson indices were calculated for each tree in R 3.0.3 (The R Foundation for Statistical Computing, Vienna, Austria). Since rarefication of the number of reads per sample did not result in any major changes in the fungal diversity patterns or community structures, we kept all observed reads in samples. BLAST searches for a representative sequence of each OTU (as determined by Mothur) were performed using PlutoF v2.0 (Abarenkov et al., 2010). Reads were blasted against the UNITE (Kõljalg et al., 2005) and INSD (Nakamura et al., 2013) databases. Resulting HTML files were combined with the abundance data obtained in Mothur using a custom Python script. This script also acquired the names of species and/or genera that resemble Latin binomials with the highest BLAST score, avoiding unidentified OTUs in the databases to be seen as best BLAST hits. Unidentified OTUs were indicated as "not applicable (NA)".

\section{4. Statistical analysis}


Statistical analyses were also carried out in R 3.0.3. Normal distributions of the residuals of models were checked with the Shapiro-Wilk test, whereas the homoscedasticity of variances were analysed using either Bartlett's or the Fligner-Killeen test. Depending on the distribution of the estimated parameters, either ANOVA or the Kruskal-Wallis rank sum test was used to check for significant differences in variances of parameters. Correlations between diversity parameters and measured environmental parameters were calculated based on Pearson's product moment correlation coefficient $\left(\mathrm{R}^{2}\right)$. Canonical Correspondence Analysis (CCA) model building was based on the cca function of the $\mathrm{R}$ package vegan and CCA analysis was based on the decorana and envfit functions of the vegan package (version 2.0-10; Oksanen et al., 2013). PERMANOVA analyses were conducted in R using the adonis function of the vegan package. Distance matrices for community data were based on BrayCurtis distances using read abundances.

\section{5. Accession numbers}

Raw SFF files were submitted to the NCBI Sequence Read Archive under accession number SRP037968 (SRA, http://www.ncbi.nlm.nih.gov/Traces/sra).

\section{RESULTS}

The 454 amplicon pyrosequencing runs resulted in a total of 460,354 raw reads across soil and root tip samples. After quality trimming and assigning reads to samples, 424,296 high-quality reads remained in the dataset.

Calculation of Good's coverage scores indicated that in $2009,95 \% \pm 0.9 \%$ (standard error) and in $201196 \% \pm 0.2 \%$ of all fungal OTUs present in soil samples in LM were detected. For the fungal communities sampled in HE, it was calculated that in $2009,96 \% \pm 0.5 \%$ of the present OTUs were sampled and $96 \% \pm 0.8 \%$ in 2011 . Good's coverage scores for root tips collected from LM trees in 2009 and 2011 were $95 \% \pm 0.6 \%$ and $96 \% \pm 0.9 \%$ respectively. Good's coverage scores for root tips collected from HE trees in 2009 and 2011 respectively were $96 \% \pm 0.2 \%$ and $97 \% \pm 0.1 \%$. These results indicate that the used sampling depth was sufficient to identify most fungal species present in both soil and root tip samples.

\section{1. Comparison of environmental parameters}

Environmental parameters were compared between the metal polluted site LM and the control site HE using one-way ANOVAs. Environmental parameters were used as dependent variables and study site or sampling year were used as fixed, independent variables. Significant differences in almost all environmental variables were found between study sites. For a few environmental variables $(\mathrm{Mg}, \mathrm{Mn}$, $\mathrm{K}$ and $\mathrm{Cu}$ in needles) small differences between sampling years were observed as well. More detailed information about differences in environmental variables between LM and HE are presented in Fig. S1.

\section{2. Comparison of soil fungal diversity parameters}

Fungal diversity parameters (OTU richness, Pielou evenness and inverse Simpson index) were compared among study sites (LM and HE) and sampling years (2009 and 2011) using one-way ANOVAs. Fungal diversity parameters were used as dependent variables and study site or sampling year as fixed, independent variables. No significant differences in fungal diversity measures between study sites or sampling years were observed (Table 1). 
Table 1. p-values resulting from one-way ANOVAs comparing fungal diversity measures between a heavy metal polluted (LM) and a non-polluted site (HE) and between two sampling years (2009 and 2011). No significant differences between LM and HE were found for any of the fungal diversity measures at the $95 \%$ confidence level.

\begin{tabular}{lcc}
\hline Fungal diversity measure & Study sites & Sampling years \\
\hline & & \\
\hline Richness & 0.70 & 0.46 \\
Inverse Simpson index* & 0.76 & 0.19 \\
Pielou Evenness** & 0.77 & 0.46 \\
\hline
\end{tabular}

* Inverse Simpson indices were log transformed.

** Pielou Evenness indices were exponentially transformed.

\section{3. Comparison of soil fungal community compositions}

Fungal community compositions in soil samples were compared between sampling years and study sites using one-way PERMANOVAs. A community distance matrix (based on Bray-Curtis distances) was used as dependent variable and study sites or sampling years were used as independent, fixed effects. Significant differences in the fungal community compositions were observed both between study sites $(\mathrm{p}<0.01)$ and sampling years $(\mathrm{p}<0.01)$.

Subsequently, a comparison was made between the fungal communities in soil samples based on the presence or absence of individual OTUs. Presence-absence of OTUs in specific combinations of sampling years and study sites are presented as a Venn diagram in Fig. S3. From this Venn diagram it is clear that of a total of 719 OTUs identified in this study, a large proportion (48.5\%) was uniquely identified in single sampling year - study site combinations. Another relatively large proportion of OTUs $(18.6 \%)$ were shared by all sampling year and study site combinations. Remarkably, all OTUs with an average relative read abundance $>1 \%$ (calculated relative to the total read abundance of a given sampling year or study site) were shared by both sampling years and study sites.

\section{4. Effects of environmental parameters on fungal diversity in soil samples}

A number of environmental factors were negatively correlated with OTU richness in soil samples in the 2011 dataset $(\mathrm{p}<0.05)$ : $\mathrm{CEC}, \mathrm{pH}\left(\mathrm{H}_{2} \mathrm{O}\right.$-derived), needle $\mathrm{Zn}$, needle $\mathrm{Cd}$ and needle $\mathrm{Cu}$ concentrations. Furthermore, a significant positive correlation $(\mathrm{p}<0.05)$ between OTU richness and soil $\mathrm{Fe}, \mathrm{Mg}$ and $\mathrm{K}$ was observed for the 2011 dataset. Whereas $\mathrm{CEC}$ and needle $\mathrm{Cu}$ concentrations were also negatively correlated with Pielou evenness indices $(\mathrm{p}<0.05)$, soil $\mathrm{Mg}$ and $\mathrm{K}$ concentrations showed a positive correlation with Pielou evenness indices in the 2011 dataset $(p<0.05)$. In the 2009 dataset, however, none of these correlations were significant. A complete list of Pearson's correlation coefficients between environmental parameters and fungal diversity indices can be found in Table S2.

\section{5. Effects of environmental parameters on soil fungal community composition}

Canonical correspondence analyses (CCA) comparing fungal community dissimilarities (based on Bray-Curtis distances) show that both in 2009 and 2011 the LM and HE communities in soil samples differ from each other (Fig. 1). Many of the measured environmental factors were found to significantly correlate with the soil fungal community compositions in both sampling years (Permutation tests; all $\mathrm{p}<0.01$; Fig. 1). Two main gradients were identified, consisting of different 
inter-correlating factors. A first gradient mainly represented the degree of metal pollution and consisted of needle $\mathrm{Zn}, \mathrm{Cd}$ and $\mathrm{Ca}$ concentrations and soil $\mathrm{Zn}$ and $\mathrm{Cd}$ concentrations. The second gradient represented soil mineral composition and included soil $\mathrm{Fe}, \mathrm{Mn}, \mathrm{Mg}$ and $\mathrm{K}$ concentrations. For the 2009 analysis, RA 1 and RA2 represented $42 \%$ and $28 \%$ of the total variation, respectively. For the 2011 analysis, RA1 and RA2 represented $34 \%$ and $27 \%$ of the total variation, respectively (Fig. 1). On the CCA plots, only the ten most abundant OTUs for each site were shown in order to prevent crowding of the graphs. The average relative abundance of the top ten most abundant fungal species identified in soil samples were compared with two-way ANOVAs (Table 2). A number of OTUs were consistently more abundant in soil samples collected in LM than in HE $(p<0.05)$. These OTUs corresponded to Suillus luteus (L.) Roussel, Sagenomella humicola (Onions \& G.L. Barron) W. Gams, Cadophora finlandica (C.J.K. Wang \& H.E. Wilcox) T.C. Harr. \& McNew, Wilcoxina mikolae (Chin S. Yang \& H.E. Wilcox) Chin S. Yang \& Korf and Inocybe lacera (Fr.) P. Kumm. OTUs that were consistently more abundant in HE soil samples $(\mathrm{p}<0.05)$ corresponded to Rhizopogon luteolus Fr., Rhizoscyphus ericae and Vonarxia vagans (Speg.) Aa. The most abundant OTU in most soil samples (both in HE and LM) corresponded to Sistotrema sp. This OTU species was found to be equally abundant in LM and HE $(\mathrm{p}=0.24)$. Also Sagenomella diversispora (J.F.H. Beyma) W. Gams was found to be equally abundant in LM and HE $(p=0.07)$. A complete list of all OTUs identified in the current study, their average relative read abundances across the entire study, BLAST scores and corresponding E-values can be found in Table S3.

Table 2 Relative read abundance (\%) of the ten most abundant fungal species (across study sites and sampling years) identified in soil samples collected from a heavy metal polluted site in LommelMaatheide (LM) and a non-polluted site in Hechtel-Eksel (HE) during two sampling years (2009 and 2011). Species not occurring in the list of ten most abundant species are grouped together as "Remaining taxa". Lifestyles of fungal species are given between brackets: ECM (ectomycorrhizal), ERM (ericoid mycorrhizal), AM (arbuscular mycorrhizal), SAP (saprotrophic), PATH (pathogenic), END (endophytic). Species with a high average, relative read abundance that are of particular interest to the current study were indicated with an asterisk $(*)$. p-values resulting from two-way ANOVAs comparing the effects of sampling site and year on the relative read abundance of the top ten most abundant species are displayed in the last three columns. Significant results are displayed in bold.

\begin{tabular}{|c|c|c|c|c|c|c|c|}
\hline Species & $\begin{array}{c}\mathrm{HE} \\
2009 \\
\end{array}$ & $\begin{array}{c}\mathrm{HE} \\
2011 \\
\end{array}$ & $\begin{array}{r}\text { LM } \\
2009 \\
\end{array}$ & $\begin{array}{c}\text { LM } \\
2011 \\
\end{array}$ & Site & Year & $\begin{array}{l}\text { Site* } \\
\text { Year }\end{array}$ \\
\hline & $\%$ & & & & $\begin{array}{l}\mathrm{p} \\
\text { values }\end{array}$ & & \\
\hline Cadophora finlandica (ECM) & 0 & 0 & 2 & 3 & $<0.01$ & 0.06 & 0.32 \\
\hline Inocybe lacera (ECM) & 0 & 1 & 4 & 4 & 0.03 & 0.74 & 0.89 \\
\hline Rhizopogon luteolus (ECM)* & 9 & 9 & 1 & 1 & $<0.01$ & 0.48 & 0.68 \\
\hline Rhizoscyphus ericae (END/ERM/ECM) & 4 & 9 & 3 & 3 & 0.02 & 0.23 & 0.25 \\
\hline Sagenomella diversispora (SAP) & 1 & 2 & 1 & 1 & 0.07 & 0.50 & 0.65 \\
\hline Sagenomella humicola (SAP) & 1 & 1 & 3 & 3 & $<0.01$ & 0.71 & 0.87 \\
\hline Sistotrema sp. (SAP/ECM)* & 51 & 33 & 18 & 45 & 0.24 & 0.66 & $<0.01$ \\
\hline Suillus luteus (ECM)* & 2 & 4 & 19 & 14 & $<0.01$ & 0.42 & 0.12 \\
\hline Vonarxia vagans (SAP/PLANT PATH) & 1 & 3 & 0 & 0 & 0.05 & 0.42 & 0.46 \\
\hline Wilcoxina mikolae (ECM)* & 5 & 6 & 11 & 10 & 0.02 & 0.98 & 0.88 \\
\hline Remaining taxa & 24 & 33 & 39 & 17 & 0.43 & 0.21 & $<0.01$ \\
\hline
\end{tabular}



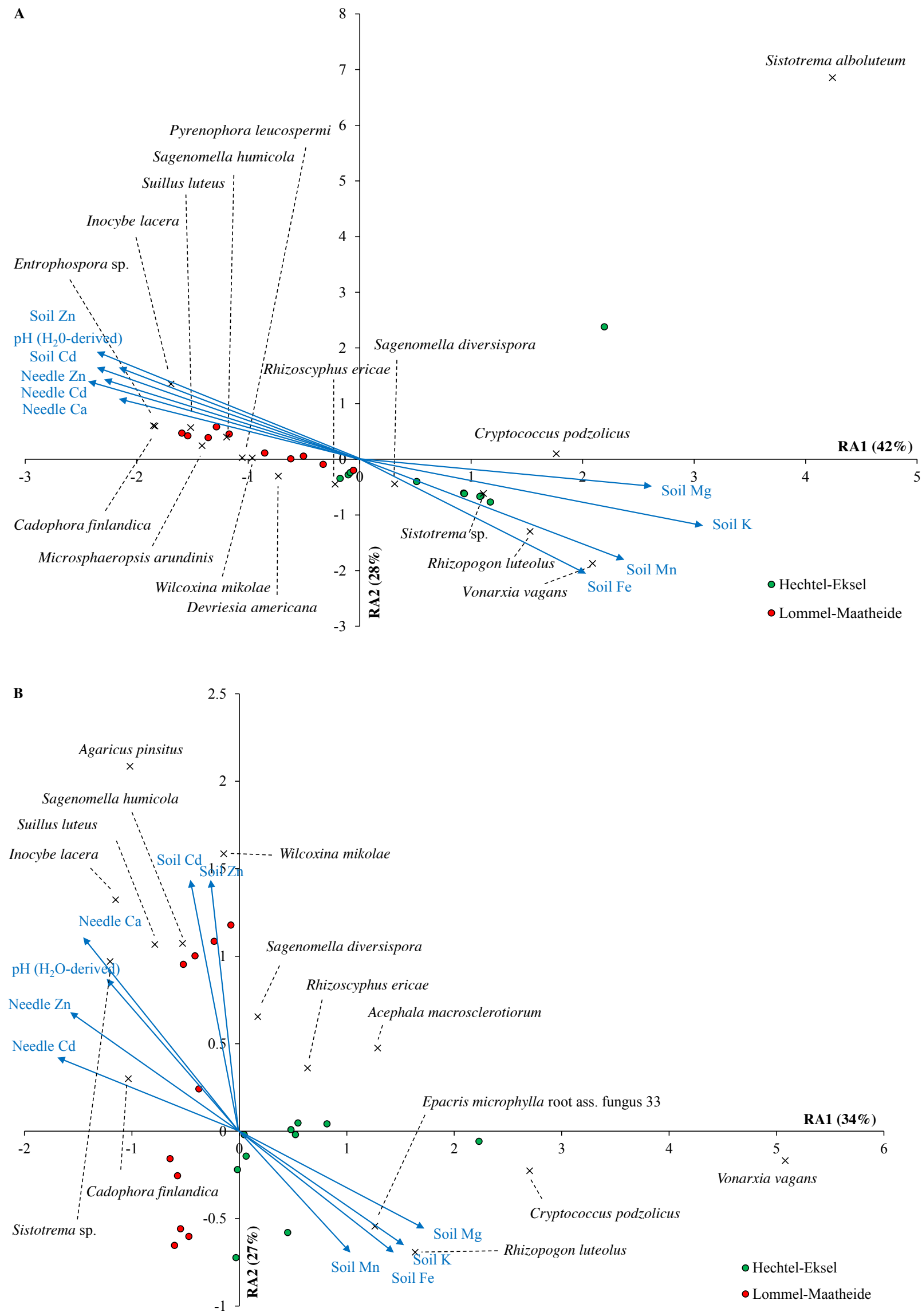

Figure 1 Results of Canonical Correspondence Analysis (CCA) correlating fungal community structures derived from soil samples (based on Bray-Curtis dissimilarities) with measured environmental parameters for a metal polluted site in Lommel-Maatheide (LM) and a control site in Hechtel-Eksel (HE) for two sampling years (2009 and 2011). A. CCA plot comparing LM (red) and HE samples (green) collected in 2009. B. CCA plot comparing LM and HE samples collected in 2011. 
Table 3 Relative read abundance (\%) of the ten most abundant fungal species (across study sites and sampling years) identified in root tip samples collected from a heavy metal polluted site in LommelMaatheide (LM) and a non-polluted site in Hechtel-Eksel (HE) during two sampling years (2009 and 2011). Species not occurring in the list of ten most abundant species are grouped together as "Remaining taxa". Lifestyles of fungal species are given between brackets: ECM (ectomycorrhizal), ERM (ericoid mycorrhizal), AM (arbuscular mycorrhizal), SAP (saprotrophic), PATH (pathogenic), END (endophytic). Species with a high average, relative read abundance that are of particular interest to the current study were indicated with an asterisk $(*)$. p-values resulting from two-way ANOVAs comparing the effects of sampling site and year on the relative read abundance of the top ten most abundant species are displayed in the last three columns. Significant results are displayed in bold.

\begin{tabular}{|c|c|c|c|c|c|c|c|}
\hline & $\begin{array}{r}\mathrm{HE} \\
2009 \\
\end{array}$ & $\begin{array}{c}\mathrm{HE} \\
2011 \\
\end{array}$ & $\begin{array}{c}\text { LM } \\
2009 \\
\end{array}$ & $\begin{array}{l}\text { LM } \\
2011 \\
\end{array}$ & Site & Year & $\begin{array}{l}\text { Site* } \\
\text { Year }\end{array}$ \\
\hline & $\%$ & & & & $\begin{array}{l}\mathrm{p} \\
\text { values }\end{array}$ & & \\
\hline Acephala macrosclerotiorum (ECM) & 1 & 8 & 2 & 2 & 0.08 & $<0.01$ & 0.09 \\
\hline Cadophora finlandica (ECM) & 4 & 0 & 9 & 6 & 0.11 & 0.45 & 0.18 \\
\hline Helotiaceae (ECM) & 11 & 7 & 0 & 1 & $<0.01$ & 0.59 & 0.71 \\
\hline Rhizopogon luteolus (ECM)* & 61 & 49 & 0 & 1 & $<0.01$ & 0.10 & 0.31 \\
\hline Rhizoscyphus ericae (END/ERM/ECM) & 5 & 8 & 13 & 10 & 0.09 & $<0.01$ & 0.43 \\
\hline Sagenomella humicola (SAP) & 3 & 0 & 4 & 1 & 0.62 & 0.41 & 0.22 \\
\hline Sistotrema sp. (SAP/ECM)* & 7 & 3 & 2 & 6 & 0.91 & 0.01 & 0.03 \\
\hline Suillus bovinus (ECM) & 0 & 0 & 8 & 3 & 0.75 & 0.75 & 0.83 \\
\hline Suillus luteus (ECM)* & 0 & 8 & 14 & 55 & $<0.01$ & $<0.01$ & $<0.01$ \\
\hline Wilcoxina mikolae (ECM)* & 0 & 0 & 23 & 5 & 0.01 & 0.55 & 0.69 \\
\hline Remaining taxa & 7 & 16 & 26 & 8 & 0.78 & 0.19 & 0.07 \\
\hline
\end{tabular}

Table 4 Relative read abundance (\%) of reads identified at the phylum level of root tip samples collected from a heavy metal polluted site in Lommel-Maatheide (LM) and a non-polluted site in Hechtel-Eksel (HE) during two sampling years (2009 and 2011). p-values resulting from two-way ANOVAs comparing the effects of sampling site and year on the relative read abundance of the top ten most abundant species are displayed in the last three columns. Significant results are displayed in bold.

\begin{tabular}{lccccccc}
\hline Phylum & HE & HE 2011 & LM 2009 & LM 2011 & Site & Year & Site*Year \\
\hline & 2009 & & \multicolumn{7}{c}{$\mathrm{p}$} \\
& & & & & \\
& values & & \\
\hline Ascomycota & 29 & 33 & 69 & 32 & 0.12 & $\mathbf{0 . 0 2}$ & 0.87 \\
Basidiomycota & 70 & 62 & 29 & 67 & 0.63 & $<\mathbf{0 . 0 1}$ & $<\mathbf{0 . 0 1}$ \\
Glomeromycota & 0 & 1 & 0 & 0 & 0.14 & 0.31 & 0.14 \\
Zygomycota & 0 & 0 & 1 & 0 & 0.34 & 0.16 & 0.34 \\
NA & 1 & 4 & 1 & 0 & $\mathbf{0 . 0 1}$ & 0.05 & $\mathbf{0 . 0 3}$ \\
\hline
\end{tabular}




\section{6. Fungal species identified from root tips}

A number of the OTUs that were identified in soil samples were also found in root tip samples (Table 3). Two-way ANOVAs were performed to compare the average relative read abundances of the top ten most abundant fungal species identified from root tip samples (Table 3). From Tables 2 and 3, it is clear that Sistotrema sp. was very dominant in soil samples in both sampling years and sites, but it never dominated on root tips. Sistotrema sp. accounted for 7\% and 3\% of all reads identified from root tips collected in HE in 2009 and 2011 respectively. Root tips collected in HE were largely dominated by Rhizopogon luteolus (accounting for $61 \%$ of all reads identified in 2009 and $49 \%$ in 2011). Other dominant OTUs identified from root tips in HE corresponded to Rhizoscyphus ericae (5\% in 2009, 8\% in 2011) and Acephala macrosclerotiorum Münzenb. \& Bubner (1\% and 8\% respectively).

In LM, Suillus luteus dominated root tip samples (accounting for $14 \%$ and $55 \%$ of all reads identified in 2009 and 2011 respectively). Also $R$. ericae was frequently identified (13\% in 2009 and $10 \%$ in 2011 ) in the LM study site, together with Wilcoxina mikolae (23\% in 2009 and 5\% in 2011), Cadophora finlandica (9\% in 2009 and 6\% in 2011), Suillus bovinus (L.) Roussel (8\% in 2009 and $3 \%$ in 2011) and Sagenomella humicola (4\% in 2009 and 1\% in 2011). At the phylum level, root tips were dominated by Ascomycota in LM in 2009, but Basidiomycota dominated the root tips of pines in 2011 in this study site. In HE, Basidiomycota dominated the root tips in both sampling years (Table 4). Two-way ANOVAs comparing the relative abundance of phyla identified on root tips are included in Table 4.

\section{DISCUSSION}

\section{1. Effects of heavy metal pollution on fungal diversity and community structure}

In the current study, we identified the belowground fungal communities in young pine stands occurring on heavy metal polluted and non-polluted soils. The pioneer fungal communities in young pine stands on heavy metal polluted and non-polluted soils consisted mainly of the same fungal species as all OTUs with a relative read abundance $>1 \%$ within a given study site and sampling year (22 OTUs) were found to be shared between both study sites and sampling years (Fig. S3). Furthermore, some of these OTUs corresponded to fungal species that typically show up in early stages of primary successions (Jumpponen et al., 1999, 2002). Spores and sclerotia are the main propagules that allow fungi to persist through unfavourable conditions and to disperse into new environments. The ECM fungus Wilcoxina mikolae and particular Suilloid fungi are known as longterm survivors in spore banks (Nguyen et al., 2012). The relative abundances of OTUs detected in soil or root samples differed markedly between the study sites, indicating a shift in the fungal community composition. Differences between the fungal communities in the soil samples of LM and HE were found to be strongly related to the presence of heavy metal pollution on the one hand and soil mineral content on the other hand (Fig. 1). These results are in line with previous studies where shifts in fungal communities have been attributed to changes in nutrient concentrations and the presence of heavy metal pollution as also found by Toljander et al. (2006) and Hui et al. (2011), respectively. On the other hand, metal pollution appears to have little or no effect on fungal diversity (Table 1) as was also observed in $\mathrm{Pb}$ contaminated soils (Hui et al., 2011).

Both in HE and LM, root tips and soil samples were found to be dominated by only a few fungal species, most of which are likely ECM species. The majority of OTUs had very low relative read abundances (relative to the total number of reads identified within the respective sampling year and study site). This abundance pattern might be typical for ECM fungal communities in primary successions (Horton and Bruns, 2001). The species abundance patterns of the root tip samples differed 
significantly from the patterns observed in soil samples, even for the most dominant fungal species that were identified (Tables 2,3). The discrepancy in occurrence of the ECM fungi identified in root tip samples and soil samples may reflect differences in exploration types and life history patterns of the different ECM fungi (Agerer, 2001; Genney et al., 2006). ECM species that produce few external hyphae may be less frequent in soil samples in contrast to species that produce more external mycelia. Saprotrophic fungi should also be more represented in soil samples. Eventually soil samples may also contain an important fraction of dormant species present as spores, sclerotia and other inactive propagules.

Root tips collected from HE were strongly dominated by Rhizopogon luteolus, whereas Suillus luteus and Wilcoxina mikolae were dominant on root tips collected in LM. These results confirm that particular Suilloid fungi and Wilcoxina mikolae are primary root colonizers of pine trees during the early stages of successions (Ashkannejhad and Horton, 2006). In LM, S. luteus becomes more frequent on root tips of the 3-year old trees, mainly at the expense of $W$. mikolae mycorrhizas. The latter species was present in the soil samples of both sites, but predominantly colonized roots in LM. Dominance of $S$. luteus was expected in the LM site since this species has been shown in the past to have developed $\mathrm{Zn}$ - and Cd-tolerant populations in the LM region (Colpaert et al., 2004; Krznaric et al., 2009). Interestingly, the dominant position of S. luteus in LM soil and root samples appears to be taken up by Rhizopogon luteolus in HE. R. luteolus occupies a very similar ecological (belowground) niche compared to S. luteus, but it may be less adapted to high metal concentrations. Previously, we recorded a higher in vitro adaptation potential for $\mathrm{Zn}$ tolerance in $S$. luteus than in $R$. luteolus (Colpaert et al., 2004). Several of the more abundant fungi in LM have been observed in metal polluted soils and other stressful environments in previous studies. These observations suggest that these fungi may exhibit substantial metabolic resistance to harsh conditions or that they have developed metal tolerance mechanisms. For example, Wilcoxina mikolae, and Inocybe lacera have been observed in metal-enriched soils in previous investigations (Prabhu et al., 1996 and Huang et al., 2012 respectively). Also Cadophora finlandica (belonging to the Phialophora/Cadophora aggregate) and Rhizoscyphus ericae (=Hymenoscyphus ericae; belonging to the Hymenoscyphus ericae aggregate) were found to be dominant species in soils as well as on roots of host plants, confirming earlier observations by Vrålstad et al. (2002), Likar and Regvar (2009) and Zhang et al. (2013), who identified fungal root colonizers from polluted environments. In soil samples from both study sites, an OTU corresponding to Sistrotrema sp. (strain B216) was found to dominate the fungal communities in both sampling years. This B216 strain was described from a primary succession of sand dunes in the United States (Ashkannejhad and Horton, 2006). In root samples, however, the Sistrotrema sp. was far less frequently identified, suggesting that this species may produce large amounts of soil mycelium or large numbers of spores or other propagules. The abovementioned fungi are interesting candidates to study metal-resistance and/or -tolerance mechanisms. Furthermore, it is possible that these ECM fungi are capable of ameliorating heavy metal toxicity in their host plants and thus exhibit plant fitness-improving characteristics in heavy metal polluted soil.

\section{2. Fungal community dynamics during early successional stages}

Differences in the observed fungal communities between sampling years suggest that colonization of soils and roots by fungi in the pioneer pine stands is still a quite dynamic process. Especially in the LM site, succession is still in a very early stage. The development of the pine root system is probably a key factor responsible for the fungal community changes. The variation in frequency of dominant species in soil and roots suggests a certain succession over the 2 years period. Pickles et al. (2010) also found both spatial and temporal differences in ECM fungal communities associated with young pines at similar spatial and temporal scales as the ones investigated in the current study. A highly dynamic fungal community may allow for the evolution of adaptive metal tolerance over short time 
spans in polluted soils. Adaptive metal tolerance is most often observed in r-strategists amongst bacteria, fungi and plants and hardly ever in $\mathrm{k}$-strategists such as woody tree species.

The dynamics of the observed fungal communities associated with pine roots were also observed at the phylum level (Table 4). Whereas the communities were dominated by Basidiomycota for both sampling years in HE, Ascomycota dominated the primary pioneer fungal communities in LM in 2009. In 2011, however, Basidiomycota became the most abundant phylum on root tips in LM. Since the first sampling session for the current study took place only one year after the pine trees were planted in LM, stress-tolerant pioneer ECM Basidiomycota were probably not sufficiently available for pine trees to be recruited. In the absence of suited Basidiomycota, more opportunistic, ectomycorrhizal and endophytic Ascomycota may colonize the available short roots. Jumpponen et al. (2002) and Cázares et al. (2005) found only few ectomycorrhizal and arbuscular mycorrhizal propagules in the younger substrates of moraine soil during the primary succession, and they observed relatively more DSE fungi on roots of pioneer plants colonising these virgin soils. During the establishment stage, heavy metals in LM may act as an additional abiotic filter selecting metal tolerant community components from the regional and ecologically suited species pool. The fact that some of the widespread dark Ascomycota may be more metal-tolerant than most Basidiomycota, as suggested by Likar and Regvar $(2009,2013)$, may explain their initial dominance in LM. Quite soon, the metal tolerant basidiomycete, Suillus luteus, becomes more frequent. From a few mycorrhizal root tips, it can develop fast growing external mycelia (long-distance exploration type) colonising the expanding root system more efficiently than the sparse propagules from the spore bank can do.

The HE site is less disturbed than the LM site and therefore HE soil may contain a somewhat richer spore bank. The absence of a toxic metal filter in HE may reduce the success of the dark Ascomycota and may favour pioneer Basidiomycota. However, it is evident that stochastic events can be quite determining in the assembly of early fungal communities during primary successions (Jumpponen, 2003). Airborne spore deposition is most likely a major factor influencing the composition of the fungal communities in our pine stands. Therefore we stress that our present conclusions on succession are based on only two time points and include only a single polluted and non-polluted site. Studies on more metal polluted sites and over longer periods remain needed to better understand the establishment and development of the belowground fungal communities.

\section{3. Conclusions}

Fungal communities thriving in pioneer pine forests in the Campine region of Belgium were shown to be dominated by a few pioneer ECM fungal species such as Sistotrema sp., Wilcoxina mikolae, Suillus luteus and Rhizopogon luteolus. Both in metal polluted and non-polluted forest soils, the same fungal species were detected, but their relative abundances differed markedly. Statistical analysis indicated the existence of two gradients that correlate well with the observed fungal community compositions. The first gradient corresponded to metal pollution and the second gradient was found to be composed of the soil minerals $\mathrm{Fe}, \mathrm{Mg}, \mathrm{Mn}$ and $\mathrm{K}$. In both metal polluted and non-polluted sites very similar diversity measures were found and all abundant species were shared between the study sites. The differences in ECM fungal community structures were attributed to abundance shifts of species that are otherwise typical for pioneer forest ecosystems. Differences between sampling years revealed a dynamic fungal community, suggesting that mycelial exploration of pioneer soils is a process with a high turnover rate.

\section{ACKNOWLEDGEMENTS}

The authors would like to thank Marc Missoorten for granting access to the study sites and for assistance during fieldwork. We would also like to thank Michael Waud for performing the 
pyrosequencing runs. Op De Beeck M. is a PhD student funded by the Research Foundation Flanders (FWO). Smits M. is a post-doc funded by the FWO. The FWO had no involvement in the study design, in the collection, analysis or interpretation of the data, in the writing of the report nor in the decision to submit the article for publication.

\section{REFERENCES}

Abarenkov, K., Tedersoo, L., Nilsson, R.H., Vellak, K., Saar, I., Veldre, V., Parmasto, E., Prous, M., Aan, A., Ots, M., Kurina, O., Ostonen, I., Jõgeva, J., Halapuu, S., Põldmaa, K., Toots, M., Truu, J., Larsson, K.H., Kõjalg, U., 2010. PlutoF - a web based workbench for ecological and taxonomic research, with an online implementation for fungal ITS sequences. Evolutionary Bioinformatics 6, 189-196.

Adriaensen, K., Vrålstad, T., Noben, J.P., Vangronsveld, J. \& Colpaert, J.V. (2005) Copper adapted Suillus luteus, a symbiotic solution for pines colonising $\mathrm{Cu}$ mine spoil. Applied and Environmental Microbiology 71, 7279-7284.

Agerer, R., 2001. Exploration types of ectomycorrhizae - A proposal to classify ectomycorrhizal mycelial systems according to their patterns of differentiation and putative ecological importance. Mycorrhiza $11,107-114$.

Ashkannejhad, S., Horton, T.R., 2006. Ectomycorrhizal ecology under primary succession on coastal sand dunes: interactions involving Pinus contorta, suilloid fungi and deer. New Phytologist 169, 345-354.

Blaalid, R., Kumar, S., Nilsson, R.H., Abarenkov, K., Kirk, P.M., Kauserud, H., 2013. ITS1 versus ITS2 as DNA metabarcodes for fungi. Molecular Ecology Resources 13, 218-224.

Bradley, R., Burt, A.J., Read, D.J., 1981. Mycorrhizal infection and resistance to heavy metal toxicity in Calluna vulgaris. Nature 292, 335-337.

Cázares, E., Trappe, J.M., Jumpponen A., 2005. Mycorrhiza-plant colonization patterns on a subalpine glacier forefront as a model system of primary succession. Mycorrhiza 15, 405-416.

Chodak, M., Gołębiewski, M., Morawska-Płoskonka, J., Kuduk, K., Niklińska, M., 2013. Diversity of microorganisms from forest soils differently polluted with heavy metals. Applied Soil Ecology 64, 714.

Colpaert, J.V., Muller, L.A.H., Lambaerts, M., Adriaensen, K., Vangronsveld, J., 2004. Evolutionary adaptation to zinc toxicity in populations of Suilloid fungi. New Phytologist 162, 549-559.

Corneo, P.E., Pellegrini, A., Cappellin, L., Roncador, M., Chierici, M., Gessler, C., Pertot, I., 2013. Microbial community structure in vineyard soils across altitudinal gradients and in different seasons. FEMS Microbiology Ecology 84, 588-602.

Ernst, W.H.O., 1990. Mine vegetations in Europe, in: Shaw, A.J. (Ed.), Heavy Metal Tolerance in Plants: Evolutionary Aspects. CRC Press, Boca Raton, pp. 21-37.

Gardes, M., Bruns, T.D., 1993. ITS primers with enhanced specificity for basidiomycetes - application to the identification of mycorrhizae and rusts. Molecular Ecology 2, 113-118.

Genney, D.R., Anderson, I.C., Alexander, I.J., 2006. Fine-scale distribution of pine ectomycorrhizas and their extrametrical mycelium. New Phytologist 170, 381-390.

Horton, T.R., Bruns, T.D., 2001. The molecular revolution in ectomycorrhizal ecology: peeking into the black-box. Molecular Ecology 10, 1855-1871.

Huang, J., Nara, K., Lian, C.L., Zong, K., Peng, K.J., Xue, S.G., Shen, Z.G., 2012. Ectomycorrhizal fungal communities associated with Masson pine (Pinus massoniana Lamb.) in $\mathrm{Pb}-\mathrm{Zn}$ mine sites of central south China. Mycorrhiza 22, 589-602.

Hui, N., Jumpponen, A., Niskanen, T., Liimatainen, K., Jones, K.L., Koivula, T., Romantschuk, M., Strömmer, R., 2011. ECM fungal community structure, but not diversity, altered in a Pb-contaminated shooting range in a boreal coniferous forest site in Southern Finland. FEMS Microbiology Ecology $76,121-132$.

Jourand, P., Ducousso, M., Loulergue-Majorel, C., Hannibal, L., Santoni, S., Prin, Y., Lebrun, M., 2010. Ultramafic soils from New Caledonia structure Pisolithus albus in ecotype. FEMS Microbiology Ecology 72, 238-249.

Jumpponen, A., 2003. Soil fungal community assembly in a primary successional glacier forefront ecosystem as inferred from rDNA sequence analyses. New Phytologist 158, 569-578. 
Jumpponen, A., Trappe, J.M., Cázares, E., 1999. Ectomycorrhizal fungi in Lyman Lake Basin: a comparison between primary and secondary successional sites. Mycologia 91, 575-582.

Jumpponen, A., Trappe, J.M., Cázares, E., 2002. Occurrence of ectomycorrhizal fungi on the forefront of retreating Lyman Glacier (Washington, USA) in relation to time since deglaciation. Mycorrhiza 12, 43-49.

Kõljalg, U., Larsson, K.H., Abarenkov, K., Nilsson, R.H., Alexander, I.J., Eberhardt, U., Erland, S., Høiland, K., Kjøller, R., Larsson, E., Pennanen, T., Sen, R., Taylor, A.F.S., Tedersoo, L., Vrålstad, T., Ursing, B.M., 2005. UNITE: a database providing web-based methods for the molecular identification of ectomycorrhizal fungi. New Phytologist 166, 1063-1068.

Krznaric, E., Verbruggen, N., Wevers, J.H.L., Carleer, R., Vangronsveld, J., Colpaert, J.V., 2009. Cdtolerant Suillus luteus: A fungal insurance for pines exposed to Cd. Environmental Pollution 157, 1581-1588.

Likar, M., Regvar, M., 2009. Application of temporal temperature gradient gel electrophoresis for characterisation of fungal endophyte communities of Salix caprea L. in a heavy metal polluted soil. Science of the Total Environment 407, 6179-6187.

Likar, M., Regvar, M., 2013. Isolates of dark septate endophytes reduce metal uptake and improve physiology of Salix caprea L. Plant and Soil 370, 593-604.

Margulies, M., Egholm, M., Altman, W.E., Attyia, S., Bader, J.S., Bemben, L.A., Berka, J., Braverman, M.S., Chen, Y.-J., Chen, Z., Dewell, S.B., Du, L., Fierro, J.M., Gomes, X.V., Godwin, B.C., He, W., Helgesen, S., He Ho, C., Irzyk, G.P., Jando, S.C., Alenquer, M.L.I., Jarvie, T.P., Jirage, K.B., Kim, J.B., Knight, J.R., Lanza, J.R., Leamon, J.H., Lefkowitz, S.M., Lei, M., Li, J., Lohman, K.L., Lu, H., Makhijani, V.B., McDade, K.E., McKenna, M.P., Myers, E.W., Nickerson, E., Nobile, J.R., Plant, R., Puc, B.P., Ronan, M.T., Roth, G.T., Sarkis, G.J., Simons, J.F., Simpson, J.W., Srinivasan, M., Tartaro, K.R., Tomasz, A., Vogt, K.A., Volkmer, G.A., Wang, S.H., Wang, Y., Weiner, M.P., Yu, P., Begley, R.F., Rothberg, J.M., 2005. Genome sequencing in microfabricated high-density picolitre reactors. Nature 437, 376-380.

Nakamura, Y., Cochrane, G., Karsch-Mizrachi, I., 2013. The international nucleotide sequence database collaboration. Nucleic Acids Research 41, D21-D24.

Nguyen, N.H., Hynson, N.A., Bruns, T.D., 2012. Stayin' alive: survival of mycorrhizal fungal propagules from 6-yr-old forest soil. Fungal Ecology 5, 741-746.

Oksanen, J., Blanchet, G.F., Kindt, R., Legendre, P., Minchin, P.R., O'Hara, R.B., Simpson, G.L., Solymos, P., Stevens, H.H., Wagner, H., 2013. Vegan: Community Ecology Package. R package version 2.0-10. http://CRAN.R-project.org/package=vegan

Op De Beeck, M., Lievens, B., Busschaert, P., Declerck, S., Vangronsveld, J., Colpaert, J.V., 2014. Comparison and validation of some ITS primer pairs useful for fungal metabarcoding studies. PLoS One 9, e97629.

Påhlsson, A.M.B., 1989. Toxicity of heavy metals $(\mathrm{Zn}, \mathrm{Cu}, \mathrm{Cd}, \mathrm{Pb})$ to vascular plants - a literature review. Water Air and Soil Pollution 47, 287-319.

Pickles, B.J., Genney, D.R., Potts, J.M., Lennon, J.J., Andreson, I.C., Alexander, I.J., 2010. Spatial and temporal ecology of Scots pine ectomycorrhizas. New Phytologist 186, 755-768.

Prabhu, V., Biolchini, P.F., Boyer, G.L., 1996. Detection and identification of ferricrocin produced by ectendomycorrhizal fungi in the genus Wilcoxina. Biometals 9, 229-234.

Rhoades, J.D., 1983. Cation exchange capacity. In: Page, A.L. (Ed.), Methods of soil analysis, Part 2 Chemical and microbiological properties, second ed. American Society Of Agronomy, Madison, pp. 149-157.

Schloss, P.D., Westcott, S.L., Ryabin, T., Hall, J.R., Hartmann, M., Hollister, E.B., Lesniewski, R.A., Oakley, B.B., Parks, D.H., Robinson, C.J., Sahl, J.W., Stres, B., Thallinger, G.G., Van Horn, D.J., Weber, C.F., 2009. Introducing mothur: open-source, platform-independent, community-supported software for describing and comparing microbial communities. Applied and Environmental Microbiology 75, 7537-7541.

Schwickerath, M., 1944. Das Hohe Venn und seine Randgebiete, Vegetation, Boden, Landschaft. Gustav Fischer, Jena, pp. 170-178.

Solís-Domínguez, F.A., Valentín-Vargas, A., Chorover, J., Maier, R.M., 2011. Effect of arbuscular mycorrhizal fungi on plant biomass and the rhizosphere microbial community structure of mesquite grown in acidic lead/zinc mine tailings. Science of the Total Environment 409, 1009-1016. 
Staudenrausch, S., Kaldorf, M., Renker, C., Luis, P., Buscot, F., 2005. Diversity of the ectomycorrhiza community at a uranium mining heap. Biology and Fertility of Soils 41, 439-446.

Tedersoo, L., Nilsson, R.H., Abarenkov, K., Jairus, T., Sadam, A., Saar, I., Bahram, M., Bechem, E., Chuyong, G., Kõljalg, U., 2010. 454 Pyrosequencing and Sanger sequencing of tropical mycorrhizal fungi provide similar results but reveal substantial methodological biases. New Phytologist 188, 291301.

Toljander, J.F., Eberhardt, U., Toljander, Y.K., Paul, L.R., Taylor, A.F.S., 2006. Species composition of an ectomycorrhizal fungal community along a local nutrient gradient in a boreal forest. New Phytologist 170, 873-884.

Turnau, K., Anielska, T., Ryszka, P., Gawroński, S., Ostachowicz, B., Jurkiewicz, A., 2008. Establishment of arbuscular mycorrhizal plants originating from xerothermic grasslands on heavy metal rich industrial wastes - new solution for waste revegetation. Plant and Soil 305, 267-280.

Vancov, T., Keen, B., 2009. Amplification of soil fungal community DNA using the ITS86F and ITS4 primers. FEMS Microbiology Letters 296, 91-96.

Vrålstad, T., Fossheim, T., Schumacher, T., 2000. Piceirhiza bicolorata - the ectomycorrhizal expression of the Hymenoscyphus ericae aggregate? New Phytologist 145, 549-563.

Vrålstad, T., Myhre, E., Schumacher, T., 2002. Molecular diversity and phylogenetic affinities of symbiotic root-associated ascomycetes of the Helotiales in burnt and metal polluted habitats. New Phytologist 155, 131-148.

Walkley, A., Black, I.A., 1934. An examination of Degtjareff method for determining soil organic matter and a proposed modification of the chromic acid titration method. Soil Science 37, 29-37.

Zhang, Y., Li, T., Zhao, Z.-W., 2013. Colonization characteristics and composition of dark septate endophytes (DSE) in lead and zinc slag heap in Southwest China. Soil and Sediment Contamination $22,532-545$.

\section{SUPPORTING INFORMATION}

Supporting Information Figure S1 Comparison of environmental variables between study sites Lommel-Maatheide (LM: metal polluted site) and Hechtel-Eksel (HE: control site) and sampling years (2009 and 2011)

Supporting Information Figure S2 Sampling design used to collect soil samples for fungal community analysis

Supporting Information Figure S3 Venn diagram showing the number of OTUs that were detected for a given study site or sampling year

Supporting Information Table S1 Primer design used to construct forward and reverse primers for 454 amplicon pyrosequencing

Supporting Information Table S2 Pearson's correlation coefficients $\left(\mathrm{R}^{2}\right)$ for correlations between OTU richness, inverse Simpson indices and Pielou evenness indices and measured environmental parameters

Supporting Information Table S3 Complete list of all OTUs that were identified in the current study with corresponding average relative read abundances, BLAST Scores and E-values 